\title{
Trapezoidal control of a coiled synchronous motor optimizing electric vehicle consumption
}

\author{
Aicha Khlissa, Houcine Marouani, Souhir Tounsi \\ School of Electronics and Telecommunications of Sfax, Sfax university (B.P. 1163, 3018 Sfax-Tunisie, Tél. : 74863047,74862500 - Fax : \\ 74863 037), Sfax, Tunisia \\ Email address: \\ aichakhlissa@gmail.com (A. Khlissa), Houcine.marouani@isecs.rnu.tn (H. Marouani), souhir.tounsi@isecs.rnu.tn (S. Tounsi) \\ To cite this article: \\ Aicha Khlissa, Houcine Marouani, Souhir Tounsi. Trapezoidal Control of a Coiled Synchronous Motor Optimizing Electric Vehicle \\ Consumption. American Journal of Electrical Power and Energy Systems. Special Issue: Design, Optimization and Control of Electric \\ Vehicles: (DOCEV). Vol. 4, No. 2-1, 2015, pp. 17-25. doi: 10.11648/j.epes.s.2015040201.13
}

\begin{abstract}
In this paper, we present a systemic trapezoidal control methodology of a coiled rotor axial flux synchronous motor dedicated to electric traction, taking into account of several constraints such as the speed limit, the energy saving, the cost of the power chain and the reliability of the whole system. Indeed the control law developed allows to impose the electromotive forces in phase with the phase currents, which reduces vehicle consumption. Also based on the technique of overfluxing during periods of high acceleration to reduce the phase current of the motor and then the vehicle consumption. This optimization technique is based on the increase of the excitation current for a given torque, thereby increasing the electric motor constant. Therefore, the phase current is lowered leading to a reduction in consumption. During the phases of constant speed operation and high decelerations, the value of the excitation current is calculated iteratively to minimize the consummation. Finally, the results obtained are with good level which encourages the electronic integration phase of this control law.
\end{abstract}

Keywords: Trapezoidal Control, Coiled Rotor Motor, Controlling Parameters, Systemic Control, Electric Vehicles

\section{Introduction}

The production of electric vehicles in large series suffers from their low autonomy, their high costs relative to combustion vehicles, and the infrastructure of batteries charging problem [1-3]. In this context, this paper addresses the problems of reducing the cost and increasing autonomy for a given stored energy. Indeed, our choice was directed towards the axial wound rotor motors with smooth pole, which is in a low-cost structure of production. Regarding the static converter, our choice fell on a structure to electromagnetic switches to low cost of production compared to its equivalent structure with IGBTs [1-3]. A trapezoidal control approach optimizing the consumption seen in increasing autonomy is developed. This approach can impose control current in phase with the back electromotive forces and use the over-fluxing technique during phases of strong accelerations to reduce consumption. The excitation current is optimized for the operating phases at constant speed and during deceleration phases as to optimize autonomy.

The paper briefly describes the choice and the design principle of the motor-converter at first time and describes the trapezoidal control strategy optimizing autonomy.

\section{Power Chain Structure}

Several configurations of power chain are shown in the literature. We cite as examples:

- The four-engine wheels configuration to direct mechanical linkage or gears.

- The configuration with two motors front or rear to direct connection or with gear.

- The single-engine configuration with mechanical differential transmission more gears or gearless. This configuration is chosen for our application because it offers the advantage of low cost, because the manufacture of a single motor is less expensive than many engines. This configuration also avoids the problem of slippage since it is impossible to control several motors at the same speed.

The power chain structure is illustrated by the figure 1 [4]. 


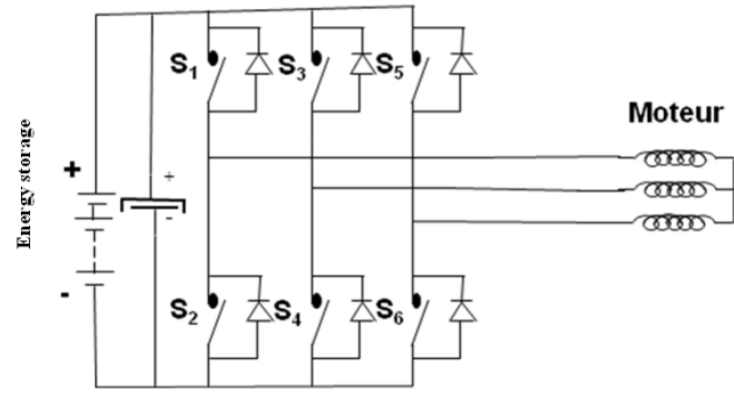

Figure 1. Power chain structure.

Usually the static converter is with IGBTs. In our case we have replaced the transistor IGBT by electromagnetic switch to push the multiple disadvantages of IGBTs.

During the phases of acceleration and constant speed operation, the motor is driven by the power converter with electromagnetic switch according to the scalar control strategy imposing the motor phase current in phase with the electromotive force, leading to a minimization of energy consumption [5], [6].

\section{Systemic Interactions}

The sizes of the motor and the converter as well as the parameters of order of the power chain are calculated according to one methodology of conception holding in account of the following interactions systems [1-12]:

- The sizing torque is calculated to the starting of the vehicle on a slope, iteratively by the method of the genetic algorithms while respecting the thermal constraints of the whole motor-converter.

- The magnetic inductions in iron are chosen close to the bends saturation to reduce the mass and thereafter the cost of the motor.

- The speed amplification report of the reducer is calculated in seen to reach the maximal speed of the vehicle with a good interpolation of the reference voltages and a reduction of the ripple torque.

- The continuous bus voltage is calculated to maximal speed to have the possibility to cover a large beach of speed.

\section{Converter Structure}

The static converter is a two-level inverter voltage. This structure is the least expensive compared to others and offers good quality of voltages and currents wave-forms, which leads to a good dynamic characteristic of EVs. Two inverter types are studied, the IGBT converter structure and the electromagnetic switches converter structure. The latter structure has the disadvantage of low switching frequency (Below $150 \mathrm{~Hz}$ ), but it is less expensive and does not pose the problem of floating potential, since each inverter arm is controlled by a single electro-magnet. Against, the IGBT structure offers the possibility to achieve a switching frequency of $8000 \mathrm{~Hz}$ which leads to a good quality of the dynamic characteristic of EVs, it present a lot of disadvantages which can be cited as examples :

- Energy losses leading to a reduced range for a stored energy also establishes the temperature rise in the transistors and diodes leading to the incorporation of a cooling system in most cases.

- The problem of potential-floating leading to a complication of the electronic control circuit.

- The intervention of capacity Trigger-emitter, Trigger-collector and Collector-emitter. These capacities occur especially at high frequencies leading to a deterioration of the quality of control signals and subsequently to performance degradation of the overall drive system

- The problem of static and dynamic Luch-up generally leading to the deterioration of the converter. In this paper we only present the design process of the converter with electromagnetic switches. Design methods of the IGBT inverter are highly processed and presented in the literature [3].

- The design parameters of the generator coil are shown in figure 2 .

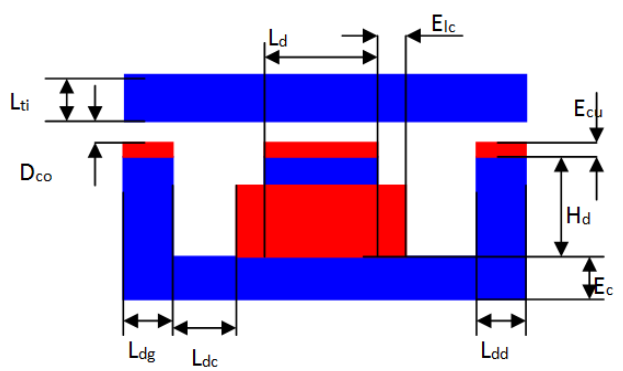

Figure 2. Design parameters of the generator coil.

For the electromagnetic switches converter structure, the electromagnet is a modular structure. Indeed, several modules can be stacked either in series or in parallel to increase the attraction force, and thereafter the opening and closing frequency of the contacts of the static converter.

The stack in parallel has the advantage that the frequency of closing and opening of the switches is clearly higher in regard to the stack in series structure, because these actions are performed by action of the attraction force of two generator coils.

The parallel stack of two modules is illustrated in figure 3 [3].

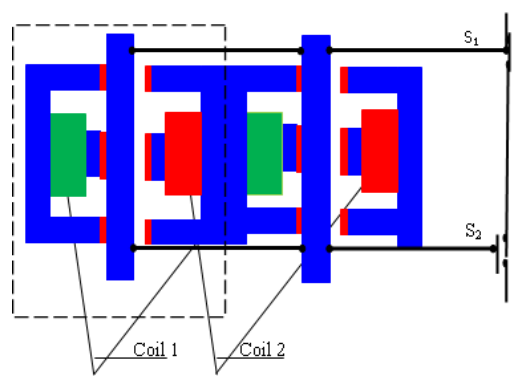

Figure 3. Stacking in parallel of two modules. 
The equation of movement of the stem is deducted from the fundamental relation of the dynamics [3]:

$$
\begin{gathered}
\mathrm{nmp} \times \mathrm{M}_{\mathrm{t}} \times \frac{\mathrm{dv}}{\mathrm{dt}}=\mathrm{nmp} \times \frac{\mu_{0} \times \mu_{\mathrm{r}}}{4} \times \frac{\mathrm{I}^{2} \times \mathrm{N}_{\mathrm{sb}}^{2}}{\left(\mathrm{E}_{\mathrm{cu}}+\mathrm{D}_{\mathrm{co}}-\mathrm{X}_{\mathrm{t}}\right)^{2}} \\
\mathrm{v}=\frac{\mathrm{dx} \mathrm{t}}{\mathrm{dt}}
\end{gathered}
$$

Where $\mathrm{v}$ and $\mathrm{M}_{\mathrm{t}}$ are respectively the velocity and the mass of the moving rod, nmp is the number of modules, $\mathrm{N}_{\mathrm{sb}}$ is the spires number of the generating coil, $\mathrm{E}_{\mathrm{cs}}$ is the thickness of the copper layer, $D_{c o}$ is the opening of the movable stem, $x_{t}$ displacement of the mobile stem and $\mu_{\mathrm{r}}$ is the relative permeability of copper.

This structure presents the time of opening and the one of closing weakest, since closing and opening of the power contacts take place joint-stock of two generating coils. The increase of the number of module increases the frequency of closing and opening of contacts, what brought us to choose only one module to push the problem of increase of the cost of the structure, slightly.

For only one module, the time of closing and opening is estimated to:

$$
\mathrm{T}_{\mathrm{on}}=\mathrm{T}_{\text {off }}=3.74 \mathrm{e}-3 \mathrm{~s}
$$

From where the frequency of closing and to the opening is estimated to:

$$
\mathrm{F}_{\mathrm{ri}}=\frac{1}{\mathrm{~T}_{\mathrm{on}}+\mathrm{T}_{\mathrm{off}}}=\frac{1}{2 \times 3.74 \mathrm{e}-3}=133.7 \mathrm{hz}
$$

In conclusion, the structure to parallel stacking with only one module is chosen for the continuation of survey.

\section{Motor-Converter Model}

The motor is supplied by a voltage inverter at two levels. IGBT transistors are replaced by ideal electromagnetic switches, to reduce losses and sink multiple disadvantages of IGBTs, such as:

- Tail current.

- The problem of floating mass leading to a complication of the control circuit.

- Static and dynamic Luch-up phenomenon leading to a deterioration of the converter in the majority of cases.

- Switching and conduction losses significant.

- Heat IGBT transistors, leading to the need for the integration of a cooling system in the most cases.

- $\quad$ Each phase of the motor is equivalent to a resistor in series with an inductance and a back electromotive force. The model of the three phases is described by the following equations [4], [5]:

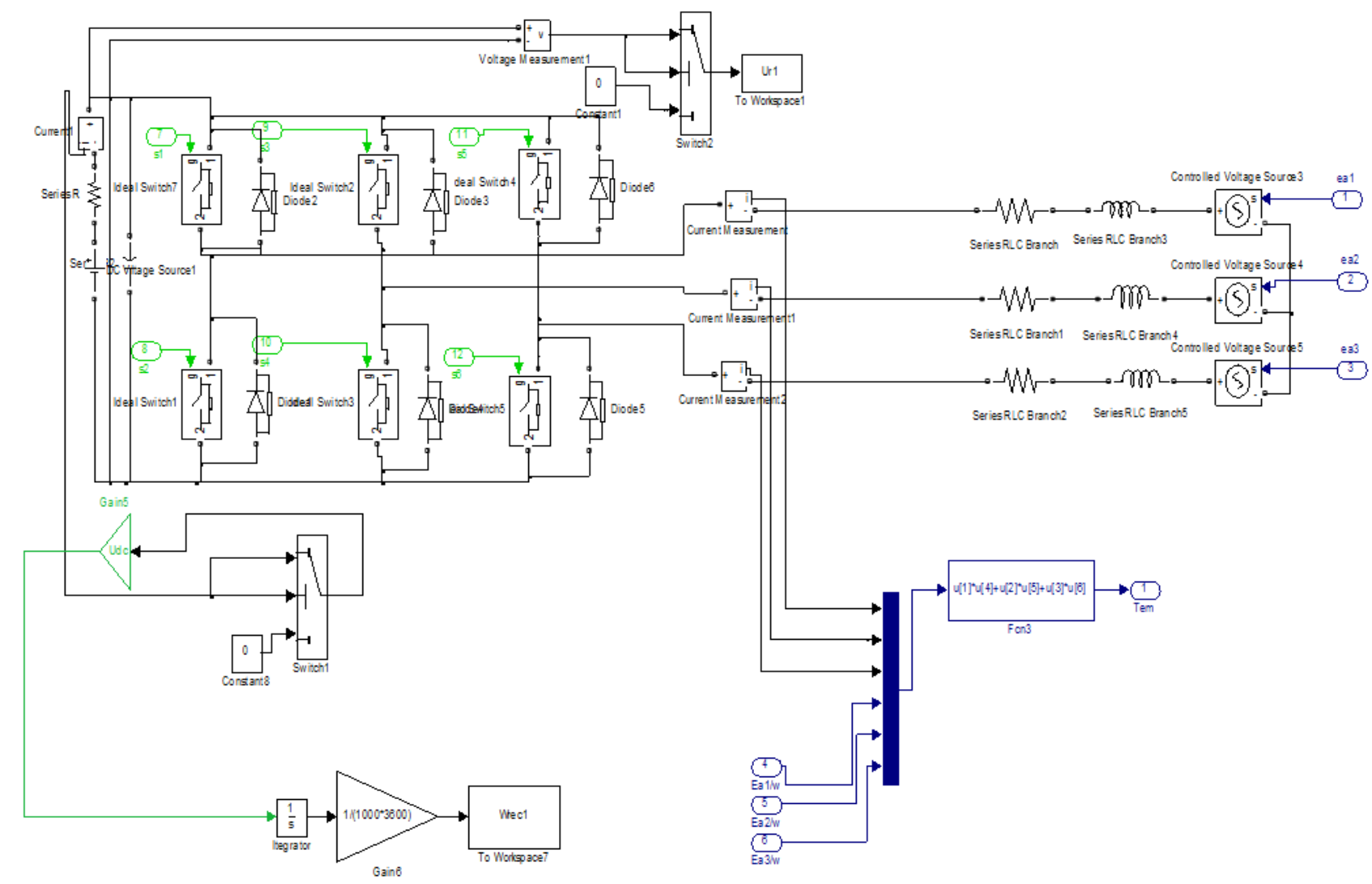

Figure 4. Simulink model of the motor-converter. 
The equations of phase voltages are expressed as follows:

$$
\begin{gathered}
\mathrm{u}_{1}=\mathrm{R}_{\mathrm{t} .} \times \mathrm{i}_{1}+\mathrm{L}_{\mathrm{t}} \times \frac{\mathrm{di}_{1}}{\mathrm{dt}}+\mathrm{e}_{1} \\
\mathrm{u}_{2}=\mathrm{R}_{\mathrm{t} .} \times \mathrm{i}_{2}+\mathrm{L}_{\mathrm{t}} \times \frac{\mathrm{di}}{\mathrm{dt}}+\mathrm{e}_{2} \\
\mathrm{u}_{3}=\mathrm{R}_{\mathrm{t} .} \times \mathrm{i}_{3}+\mathrm{L}_{\mathrm{t}} \times \frac{\mathrm{di}_{3}}{\mathrm{dt}}+\mathrm{e}_{3} \\
\mathrm{~L}_{\mathrm{t}}=\mathrm{L}-\mathrm{M}
\end{gathered}
$$

Where $\mathrm{e}_{1}, \mathrm{e}_{2}$ and $\mathrm{e}_{3}$ are respectively the electromotive forces of the phases 1, 2 and 3, $\mathrm{L}$ is the phase inductance and $\mathrm{M}$ is the mutual inductance.

The electromagnetic torque is given by the following equation:

$$
\mathrm{T}_{\mathrm{em}}=\frac{1}{\Omega}\left(\mathrm{e}_{1} \times \mathrm{i}_{1}+\mathrm{e}_{2} \times \mathrm{i}_{2}+\mathrm{e}_{3} \times \mathrm{i}_{3}\right)
$$

Motor model is implanted under Matlab / Simulink as shown in the figure 4 :

\section{Speed Regulator}

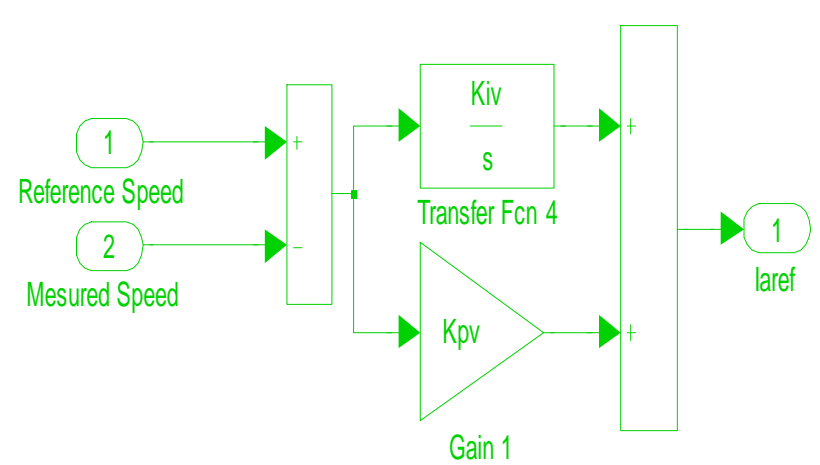

Figure 5. Simulink model of the speed regulator.

The comparison of the reference speed and the response speed provides the amplitude of the reference currents minimizing the error between the reference speed and the speed of response. Indeed, the reference speed is compared to the response speed. The comparator attacks a proportional-integral-type (PI regulator) to provide the amplitude of reference currents minimizing the speed error. The Simulink model of speed regulator is illustrated by the figure 5 .

\section{Currents Regulators}

The reference current generator allows generating three currents with trapezoidal shapes and phase shifted relative to each other by an angle equal to $120^{\circ}$ electrical. This three phase currents are out in phase with electromotive forces to minimize consumption and its amplitudes are controlled by the speed controller. Three control loops are used to convert currents to the three reference voltages of the motor.

The model of the reference current generator is implanted under the environment of Matlab / Simulink as shown according to the figure 6 :

\section{Model of the Back Electromotive Forces}

The three back electromotive forces are estimated from the following three equations:

$$
\begin{aligned}
& \mathrm{a}=\cos \left(\mathrm{p} \times \Omega \times \mathrm{t}+\frac{\pi}{2}\right) \\
& \mathrm{b}=\cos \left(\mathrm{p} \times \Omega \times \mathrm{t}-\frac{2 \times \pi}{3}+\frac{\pi}{2}\right) \\
& \mathrm{c}=\cos \left(\mathrm{p} \times \Omega \times \mathrm{t}-\frac{4 \times \pi}{3}+\frac{\pi}{2}\right)
\end{aligned}
$$

The models of the back electromotive forces $\left(\mathrm{e}_{1}, \mathrm{e}_{2}, \mathrm{e}_{3}\right)$ are estimated from the following algorithm:

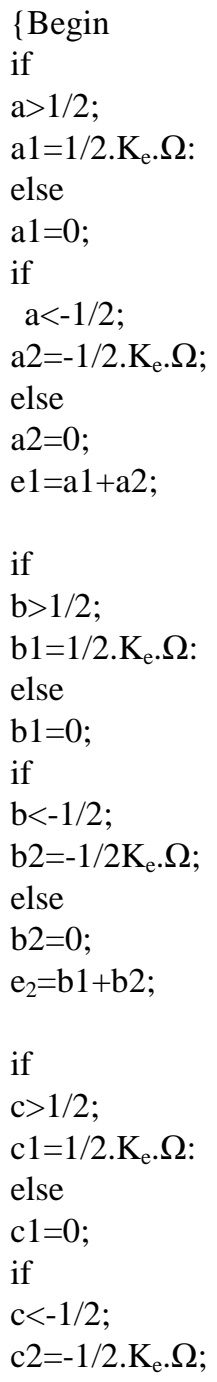


else

c2 $=0$

$\mathrm{e}_{3}=\mathrm{c} 1+\mathrm{c} 2$;

end $\}$.

With $\mathrm{K}_{\mathrm{e}}$ is the back electromotive constant and $\Omega$ is the motor angular speed.

The Simulink model of the back electromotive forces is illustrated by the figure 7 .

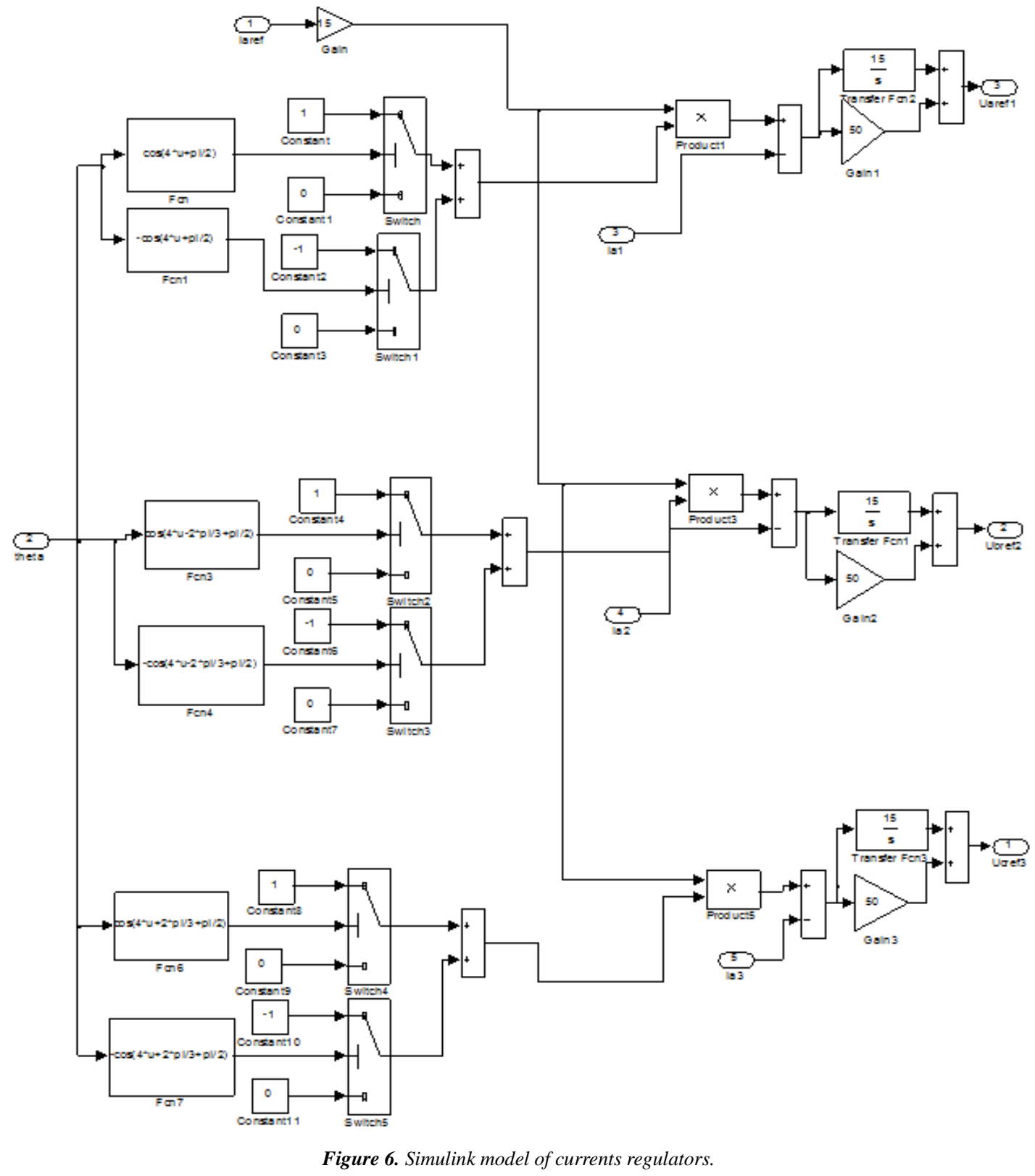




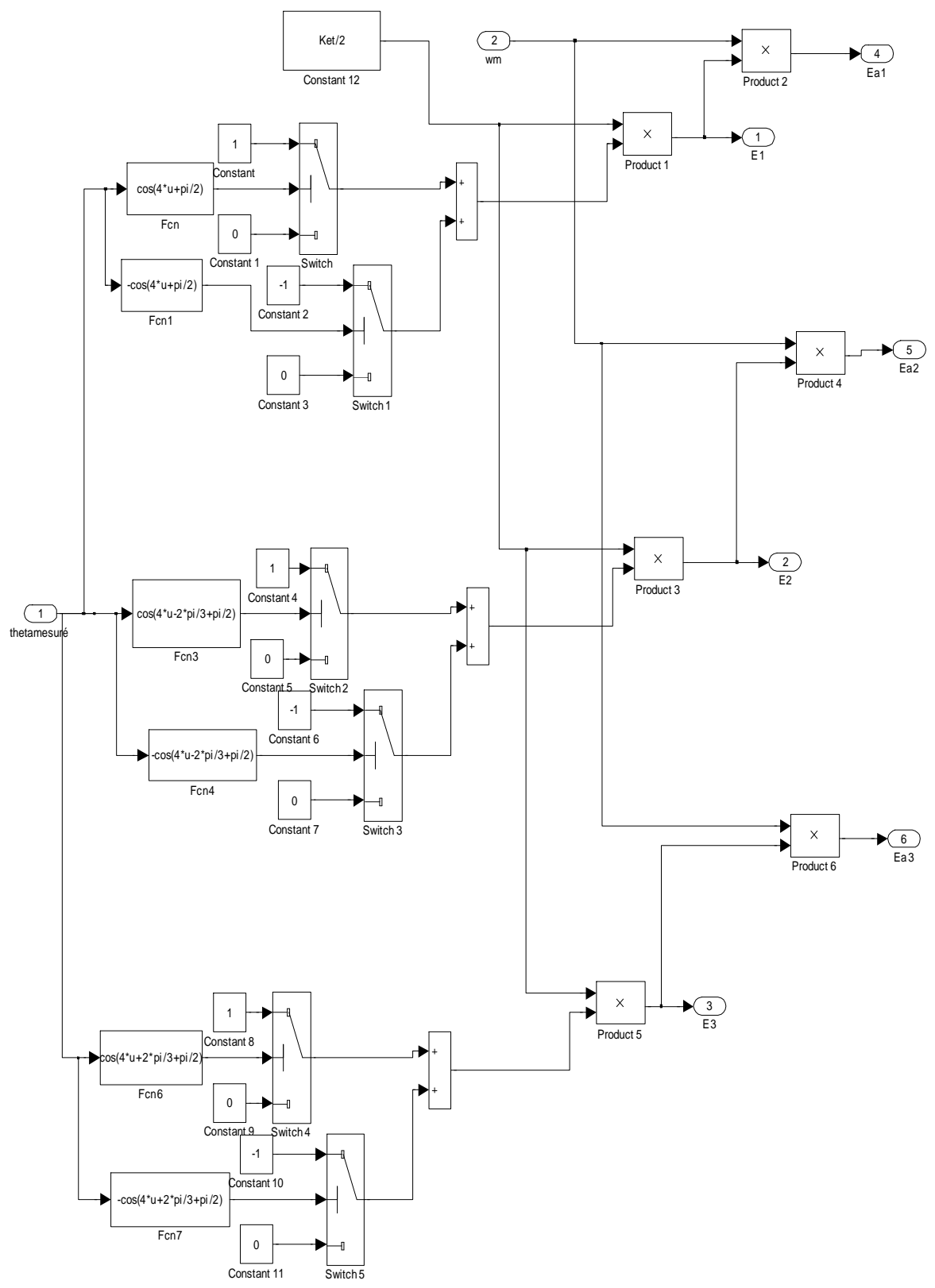

Figure 7. Simulink model of the back electromotive forces.

\section{Control Signals Generator}

The control signal generator compares the three reference voltages to a triangular signal with frequency significantly higher than the frequency of the voltages provided by the currents regulators. The output of each comparator attack an hysteresis variant between 0 and 1 for outputting the signals for controlling the switches S1, S3 and S5 . The speed controller and current controller adjusts the pulse width of the control signals so as to impose currents in phase with the electromotive forces against and minimize the error between the reference speed and the speed of response. Signals for controlling the switches S2, S4 and S6 are respectively complementary to the signals S1, S3 and S5. To prevent short circuits, control pulses S2, S4 and S6 are shortened to avoid duplication between two signals control arm. The delay to the closing of the power switch is held in account by the proposed model. The Simulink model of the generator control signals is shown in figure 8:

\section{Dynamic Equation}

The dynamic equation of the vehicle is derived from the fundamental relationship of dynamics:

$$
\left(\mathrm{M}_{\mathrm{v}} \times \mathrm{R}_{\mathrm{r}}\right) \times \frac{\mathrm{dv}}{\mathrm{dt}}=\mathrm{r}_{\mathrm{d}} \times \mathrm{T}_{\mathrm{m}}-\left(\mathrm{F}_{\mathrm{r}}+\mathrm{F}_{\mathrm{a}}+\mathrm{F}_{\mathrm{c}}\right) \times \mathrm{R}_{\mathrm{r}}
$$

The equation of motion of the vehicle is implemented under the environment of Matlab/ Simulink as shown in to the figure 9: 


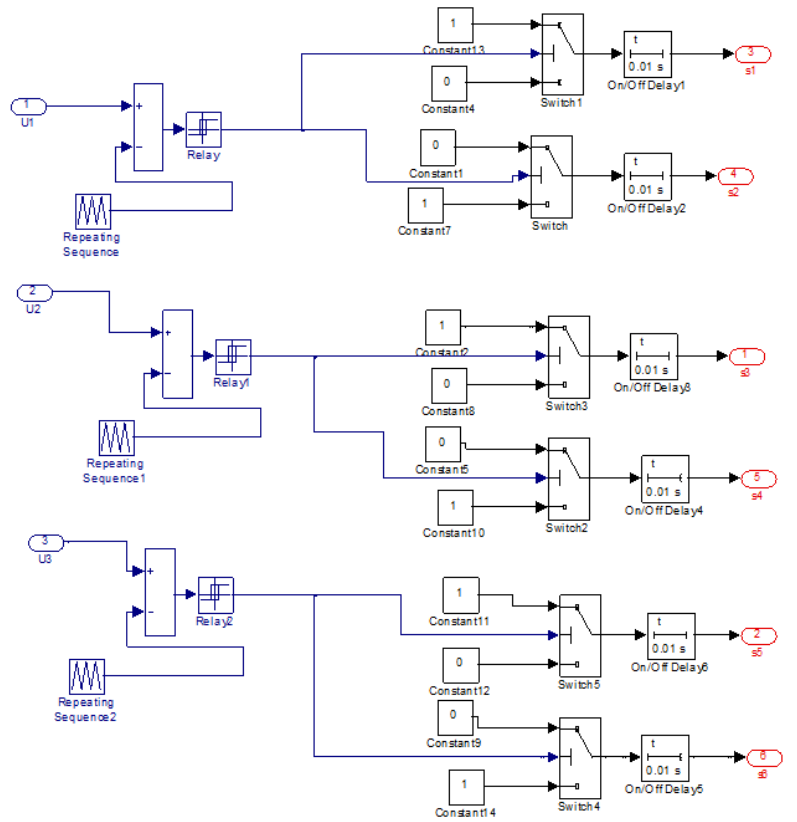

Figure 8. Simulink model of control signals generator.

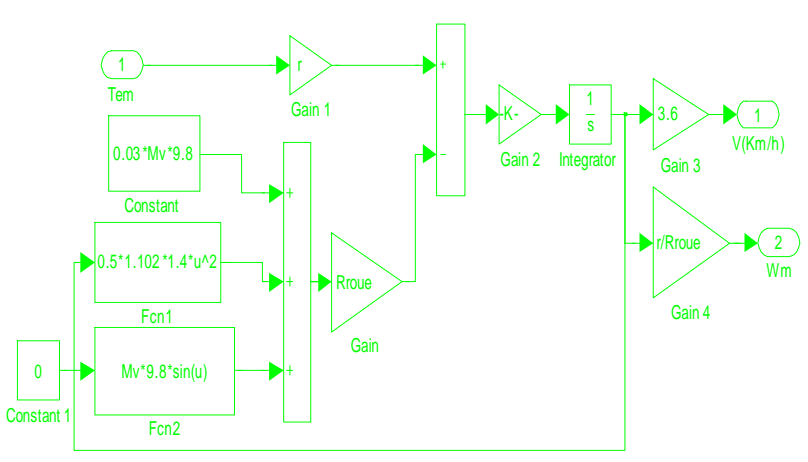

Figure 9. Simulink model of the dynamic equation.

\section{Excitation System Optimizing Consumption}

The excitation system use the over-fluxing technique during phases of strong accelerations to reduce consumption (Excitation current augmentation). The excitation current is optimized for the operating phases at constant speed and during deceleration phases as to optimize autonomy (figure $10)$.

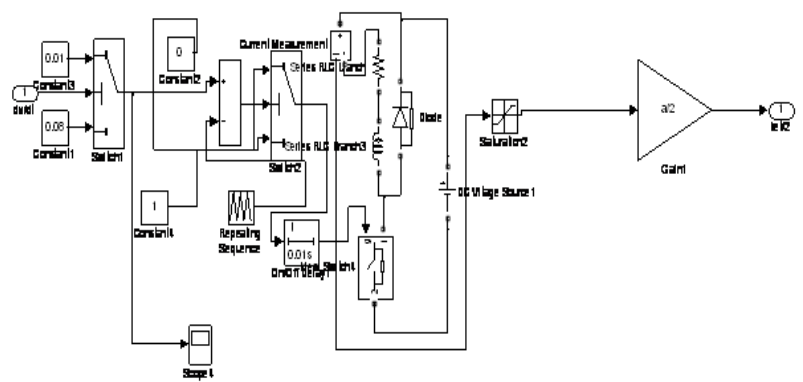

Figure 10. Excitation system.

\section{Global Model of the Power Chain}

The coupling of different models of the electric vehicle power chain leads to overall model implemented under the environment of Matlab/ Simulink as shown in to the figure 11 [9-12]:

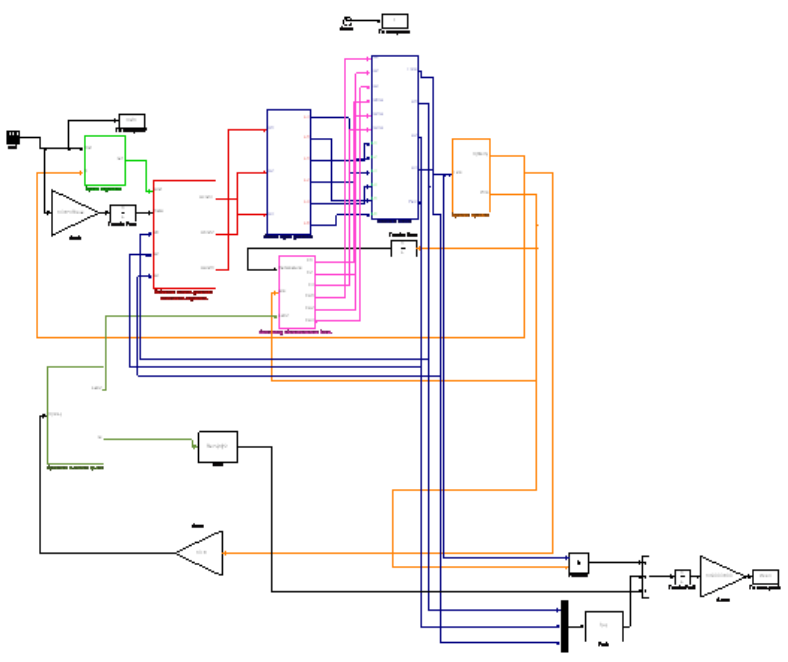

Figure 11. Global model of the power chain.

\section{Descriptions of the Simulations Results}

Scalar control has the disadvantage of convergence at startup, but for the electric car application, the acceleration during start-up is reduced to avoid the problem of abrupt starting and to increase the reliability of the vehicle. This property makes it very robust the scalar control for electric car application. This feature is illustrated in Figure 12. Also this figure shows that the speed of response precisely follows the reference speed, which shows the performance of the control technique chosen. This characteristic validates design process of the power chain.

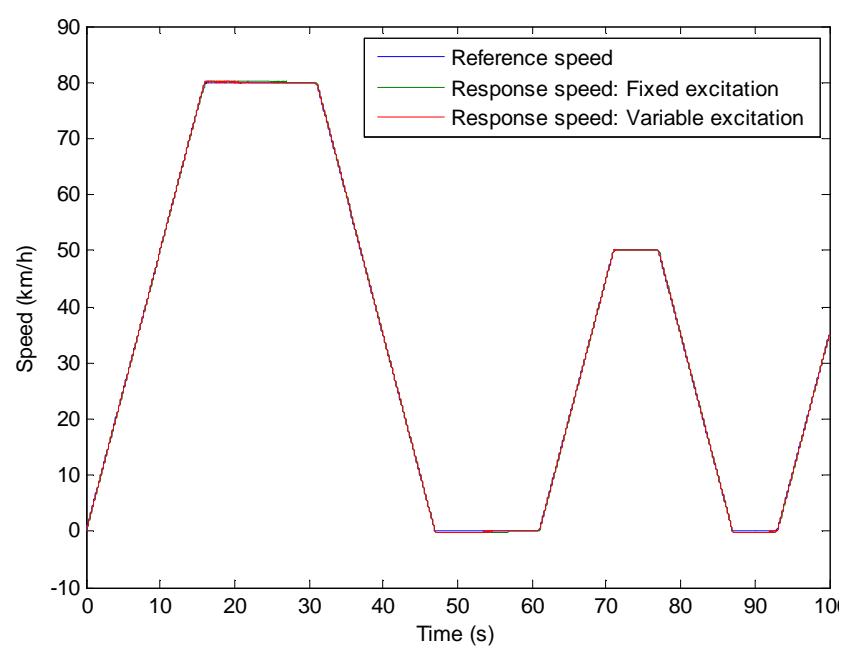

Figure 12. Speed response. 
Figure 13 shows that the starting current is significantly reduced, which shows the good choice of the parameters of speed and currents regulators.

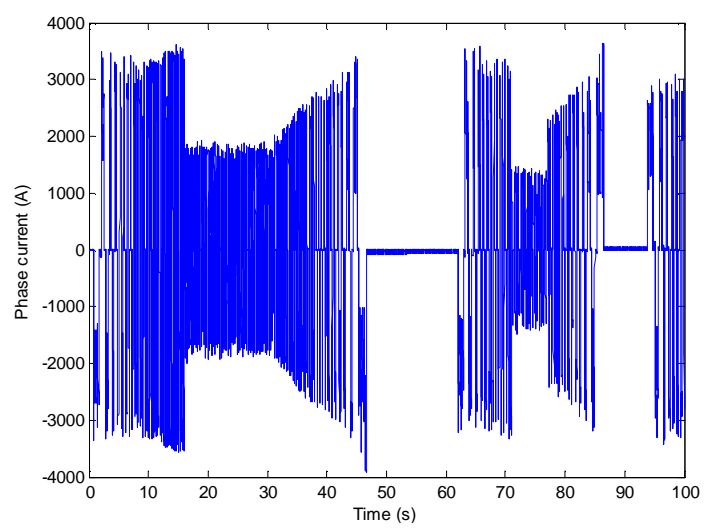

Figure 13. Phase current.

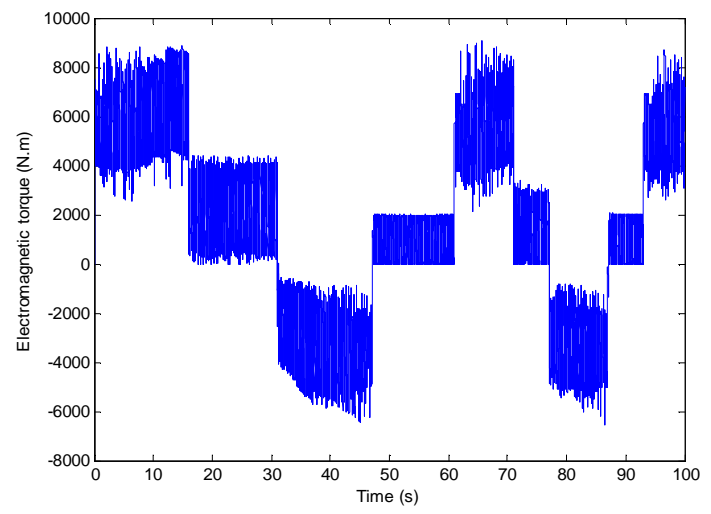

Figure 14. Torque on the motor shaft.

Figure 14 shows that the torque on the motor shaft is negative during deceleration, since the inertia of the drive power is negative.

The electric vehicle recovers energy hang deceleration phases. This property is illustrated by figure 15 .

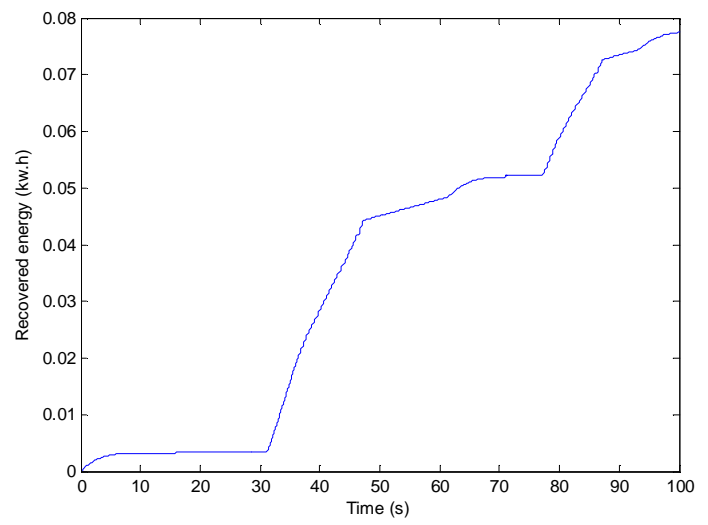

Figure 15. Energy recovered.

The control law imposes a phase shift ideally zero to minimize consumption, but in reality this phase shift is close to zero since the time constant of the motor is not zero. This property is illustrated by figure 16 :

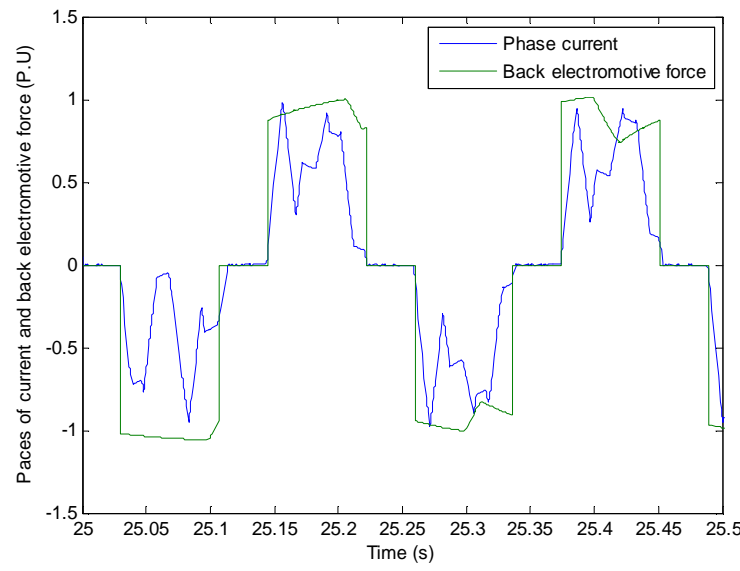

Figure 16. Paces of current and back electromotive force.

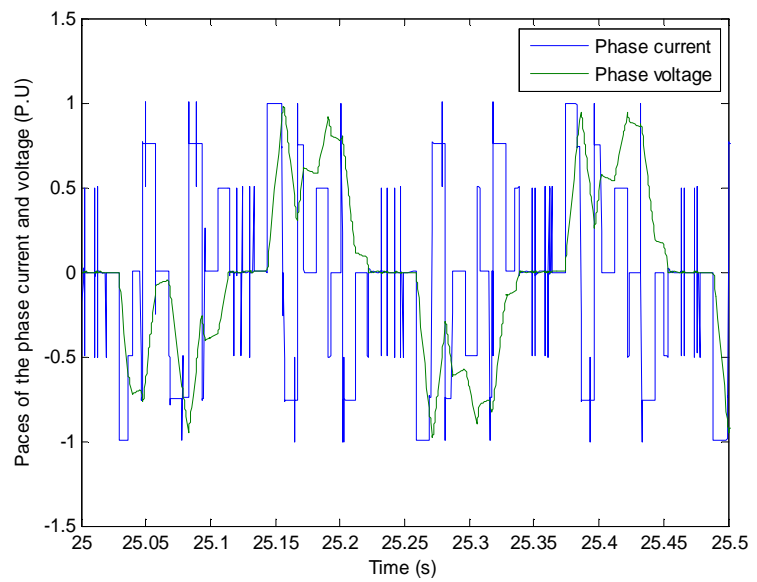

Figure 17. Paces the phase voltage and back electromotive force.

The figure 17 shows that the shape of the current is near to trapezoidal shape, which shows the effectiveness of the selected control law. The distortion in the shape of the current is essentially owed to the delay to the closing of the power contacts.

The current of excitation presents its elevated values during the phases of strong acceleration to minimize electric vehicle consumption (figure 18)

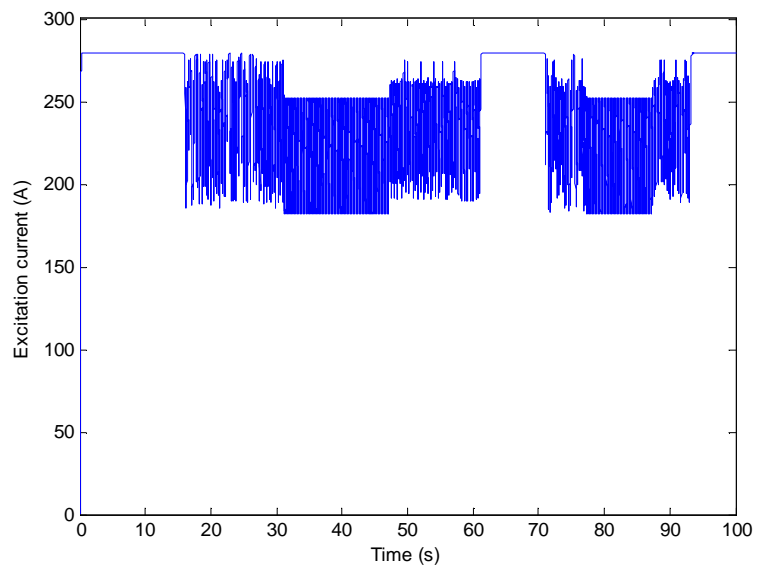

Figure 18. Excitation current. 
The electric vehicle recovers energy hang deceleration phases. This property is illustrated by figure 19 and 20 .

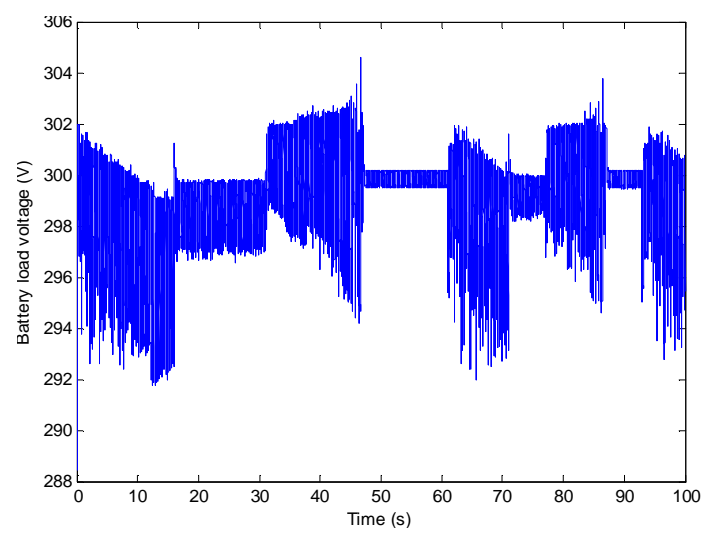

Figure 19. Battery load voltage.

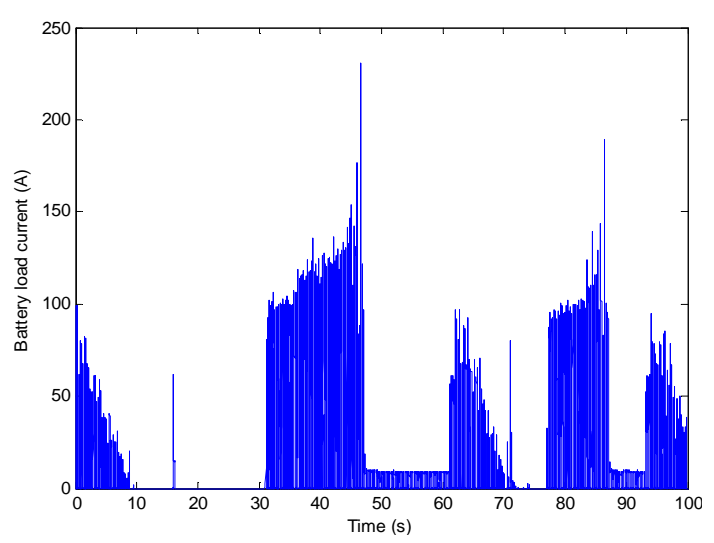

Figure 20. Battery load current.

The figure 21 shows that the system with optimized excitation permits a non negligible reduction of the consummation.

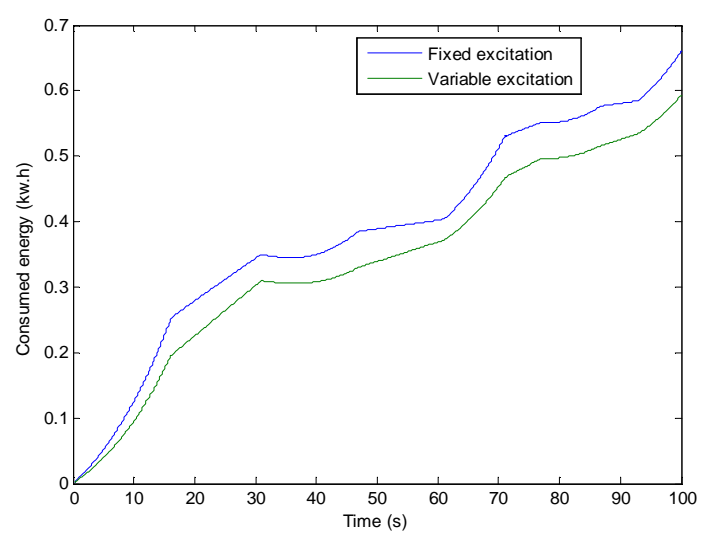

Figure 21. Consumed energy.

\section{Conclusion}

In this paper we present a systemic trapezoidal control a coiled rotor synchronous motor with reduced pruction cost. This methodology takes into account the interactions between the control and the design of the motor-converter. The system modeling along with a trapezoidal control law under the environment of Matlab / Simulink, validates this design approach and leads to a scientific results to good level. As future work, it will be interesting to start the problem of excitation system parameters optimization.

\section{References}

[1] S. TOUNSI, «Modélisation et optimisation de la motorisation et de l'autonomie d'un véhicule électrique», Thèse de Doctorat 2006, ENI Sfax.

[2] S. TOUNSI et R. NEJI: «Design of an Axial Flux Brushless DC Motor with Concentrated Winding for Electric Vehicles», Journal of Electrical Engineering (JEE), Volume 10, 2010 Edition: 2, pp. 134-146.

[3] S. TOUNSI, M. HADJ KACEM et R. NEJI « Design of Static Converter for Electric Traction », International Review on Modelling and Similations (IREMOS) Volume 3, N. 6, December 2010, pp. 1189-1195.

[4] S. TOUNSI « Losses modelling of the electromagnetic and IGBTs converters », International Int. J. Electric and Hybrid Vehicles (IJEHV), Vol. 5, No. 1, 2013, pp:54-68.

[5] S. TOUNSI « Comparative study of trapezoïdal and sinusoïdal control of electric vehicle power train», International Journal of Scientific \& Technology Research (IJSTR), Vol. 1, Issue 10, Nov 2012.

[6] [M. HADJ KACEM, S. TOUNSI, R. NEJI «Systemic Design and Control of Electric Vehicles Power Chain », International Journal of Scientific \& Technology Research (IJSTR), Vol. 1, Issue 10, Nov 2012.

[7] S. TOUNSI « Control of the Electric Vehicles Power Chain with Electromagnetic Switches Reducing the Energy Consumption», Journal of Electromagnetic Analysis and Applications (JEMAA) Vol.3 No.12, December 2011.

[8] S. TOUNSI, M. HADJ KACEM et R. NEJI « Design of Static Converter for Electric Traction », International Review on Modelling and Similations (IREMOS) Volume 3, N. 6, December 2010, pp. 1189-1195.

[9] S. TOUNSI et R. NEJI: "Design of an Axial Flux Brushless DC Motor with Concentrated Winding for Electric Vehicles", Journal of Electrical Engineering (JEE), Volume 10, 2010 Edition: 2, pp. 134-146.

[10] S. TOUNSI, R. NEJI, and F. SELLAMI: "Design Methodology of Permanent Magnet Motors Improving Performances of Electric Vehicles", International Journal of Modelling and Simulation (IJMS), Volume 29, $\mathrm{N}^{\circ}$ 1, 2009.

[11] A. Moalla, S. TOUNSI et R. Neji: "Determination of axial flux motor electric parameters by the analytic-finite elements method", 1nd International Conference on Electrical Systems Design \& Technologies (ICEEDT'07), 4-6 Novembre, Hammamet, TUNISIA.

[12] N. Mellouli, S. TOUNSI et R. Neji: "Modelling by the finite elements method of a coiled rotor synchronous motor equivalent to a permanent magnets axial flux motor", 1nd International Conference on Electrical Systems Design \& Technologies (ICEEDT'07), 4-6 Novembre, Hammamet, TUNISIA. 